\title{
ERP priming studies of bilingual language processing
}

\author{
Bosch, Sina
}

2018-05

Bosch , S \& Leminen, A 2018 , ' ERP priming studies of bilingual language processing ' ,

Bilingualism , vol. 21 , no. 3 , pp. 462-470 . https://doi.org/10.1017/S1366728917000700

http://hdl.handle.net/10138/310202

https://doi.org/10.1017/S1366728917000700

cc_by_nc_nd

acceptedVersion

Downloaded from Helda, University of Helsinki institutional repository.

This is an electronic reprint of the original article.

This reprint may differ from the original in pagination and typographic detail.

Please cite the original version. 
Running Head: ERP Priming in Bilinguals

Title: ERP Priming Studies of Bilingual Language Processing*

Authors: Sina Bosch ${ }^{1}$ and Alina Leminen ${ }^{2}$

1) Potsdam Research Institute for Multilingualism, University of Potsdam, 14476, Potsdam, Germany

2) Cognitive Brain Research Unit, Department of Psychology and Logopedics, Faculty of Medicine, University of Helsinki, Helsinki, 00014

*Acknowledgments:

Our work in this article has been supported by an Alexander-von-Humboldt Professorship to Harald Clahsen. We thank the BLC Editors and reviewers as well as the members of the Potsdam

Research Institute for Multilingualism for their thoughtful and constructive comments on earlier versions of our manuscript.

Address of Correspondence:

Sina Bosch

Potsdam Research Institute for Multilingualism

Karl-Liebknecht-Straße 24-25

14476 Potsdam

Germany

Email: bosch@uni-potsdam.de 


\section{Abstract}

The aim of this review is to provide a selective overview of priming studies which have employed the event-related brain potential (ERP) technique in order to investigate bilingual language processing. The priming technique can reveal an implicit memory effect in which exposure to one stimulus influences the processing of another stimulus. Behavioral approaches, such as measuring reaction times, may not always be enough for providing a full view on the exact mechanisms and the time-course of language comprehension. Instead, ERPs have a time-resolution of a millisecond and hence, they offer a precise temporal overview of the underlying neural processes involved in language processing. In our review, we summarize experimental research which has combined priming with ERP measurements, thus creating a valuable tool for examining the neurophysiological correlates of language processing in the bilingual brain.

Keywords: Event-related brain potentials, priming, bilinguals 


\section{Introduction}

Previous priming research on second language (L2) processing has yielded a controversial picture on how two or more languages are processed with respect to each other. While many behavioural studies have reported persisting difficulties even in advanced L2 speakers in the syntactic (Johnson \& Newport, 1989; Weber-Fox \& Neville, 1996), phonological (Flege, MacKay \& Meador, 1999), and morphological (Krause, Bosch \& Clahsen, 2015) domains, there are several studies which have reported native-like linguistic skills in these domains (e.g. Birdsong, 1992; Bosch \& Clahsen, 2016). However, it is worth noting that the absence of observed differences in behavioural measures taken from L1 and L2 speakers of a target language does not necessarily mean that the underlying neural computation mechanisms are also of the same nature. Likewise, different behavioural priming patterns between L1 and L2 are not necessarily the result of different neural generators. Hence, the application of neurophysiological measures can add valuable information about the timing and degree of activation of brain networks, which offers an insight into the underlying structures and processing mechanisms of L2 language processing.

Over the past years, an increasing number of studies examining bilingual language processing has used event-related brain potentials (ERPs), combined with the priming technique in order to investigate the neural substrates of bilingual real-time language comprehension. Priming has been defined as an implicit memory effect in which exposure to one stimulus influences the reaction to another stimulus. For instance, linguistic relationships between different complex word forms, such as morphologically complex words (e.g. walked, saw), have been experimentally approached with the priming paradigm in order to investigate to what extent a prior presentation of a complex word (e.g. walked) as a prime facilitates the recognition of an identical (e.g. walked), related (e.g. walk), or unrelated (e.g. laughed) target form. A robust finding has been that the presentation of related primes is advantageous for the 
recognition of the target (relative to unrelated primes) due to an effective preactivation of the relevant lexical entry.

ERPs are small scalp-recorded voltage changes in the electroencephalogram (EEG), which are precisely time- and phase-locked to a presented stimulus of an experiment. While behavioral data reflect only final reaction times, ERPs allow a detailed analysis of the underlying neurophysiological mechanisms and of the time-course of the cognitive processes involved in language processing. The additional benefit that comes from including ERP measurements in traditional behavioral priming studies lies in their ability to track down subtle (viz. early, and possibly automatic) neurocognitive effects involved in language processing and tease them apart from later (attentional and also behaviorally evident) processing effects. Thierry and $\mathrm{Wu}$ (2007), for example, demonstrated modulations of ERP effects for experimental data which did not produce modulations in participants' behavioral performance (a more thorough review of Thierry and Wu's (2007) study is provided subsequently). Hence, data from pure priming experiments with reaction time (RT) and accuracy measurements provide only indirect evidence for underlying cognitive processes, since they might, for example, be mediated by motor-responses. In contrast, ERPs measure cortical responses on a millisecond scale, and therefore, ERP data enable researchers to tap brain processes involved in lexical access in real time, and continuously across a whole trial, long before a motor response is initiated.

The following sections provide a selective review of studies which have assessed the cognitive processes involved in bilingual language comprehension and which combined both traditional behavioral priming techniques and real-time ERP measurements. The main focus of the research presented here will be on language processing during word-level reading. While exposure to individual words without linguistic context is a rather unconventional reading situation for a bilingual language user, assessment of L1 and L2 readers' processing of isolated words provides insight into the underlying mechanisms during lexical access. In 
addition, it allows elucidating the acquisition and integration of new lexical representations for an L2, as well as their interaction with already existing representations from an L1. In general, the use of ERP measurements to examine the computation of isolated words during reading comprehension has proven to be a useful way of tapping into the time-course of the underlying neurocognitive processes necessary for efficient word recognition in both monolingual and bilingual settings (for a review, see Dunabeitia, Dimitropoulou, Gillon Dowens, Molinaro \& Martin, 2016). This review will be organized on the basis of whether ERP evidence has been acquired in a single or in a dual language context.

\section{Bilingual language processing in single-language contexts}

Experimental studies from a single language context, in which experimental stimuli from only one of the two languages of a bilingual speaker are presented in a single experimental trial, can provide information on the comparison of L1 versus L2 language processing. The only way in which properties of the non-target language can influence the processing of the target language is by automatically activating representations of the task-irrelevant language. Hence, single-language contexts can potentially reveal the extent of automatic co-activation of lexical representations in the two languages of a bilingual speaker. In particular, by making use of electrophysiological measures, it is possible to tackle down the exact word processing stages at which bilingual language activation takes place. 
Research on morphological ERP priming

The study of different domains of language processing has been associated with distinct ERP components describing functional processes in the human brain. For example, basic repetition priming effects, i.e. the repeated presentation of identical prime and target words, have been argued to elicit a widespread positivity with an onset latency between $200 \mathrm{~ms}$ and 300ms which can have a duration of several hundred milliseconds (see Rugg, 1995 for a review). This effect has been related to a reduction of the N400 component on target words preceded by identical or related prime words relative to unrelated primes. The N400 is likely the most extensively studied ERP component directly linked to language processing (Mueller, 2005 , p.155). On the one hand, studies have repeatedly shown that the N400 increases as a function of predictability of a word within its semantic context, which can range from a single word to general world knowledge (Kutas \& Federmeier, 2000). The functional role of the N400 has therefore been assumed to be related to semantic processing, particularly to access to semantic memory representations (e.g. Kutas \& Federmeier, 2000; 2011), semantic integration or unification (Hagoort, Baggio \& Willems, 2009). On the other hand, previous L1 research has shown that the N400 component is also sensitive to morphological manipulations (e.g., Leminen \& Clahsen, 2014; Weyerts, Münte, Smid \& Heinze, 1996; Rodriguez-Fornells, Münte \& Clahsen, 2002; Münte, Say, Clahsen \& Kutas, 1999; Lavric, Clapp, \& Rastle, 2007; Morris, Frank, Grainger \& Holcomb, 2007; Morris, Grainger \& Holcomb, 2008). That is, differences in N400 responses have been observed both in repetition priming of regularly vs. irregularly inflected words (e.g., Dominguez et al., 2004; Münte et al., 1999; RodriguezFornells et al., 2002; Weyerts et al., 1996) and in visual and auditory lexical decision tasks between otherwise matched inflected vs. monomorphemic words (Lehtonen et al., 2007; Leinonen et al., 2009). The reduced N400 for related prime-target pairs has been interpreted as a repetition-priming effect due to morphological decomposition of the prime word (e.g., 
[walk]+[-ed]). Hence, a target word such as 'walk' is easy to access, since it overlaps with the memory trace formed by the corresponding prime ('walk'), yielding the reduced N400 (but see e.g., Kielar and Joanisse (2010, 2011) for a different account).

ERP priming studies on morphological processing in L2 are still rather scarce. De Diego Balaguer et al. (2005) investigated to what extent similarities across languages may play a crucial role in the acquisition and processing of morphosyntactic information. They tested the processing of regular and irregular verbal inflection of Spanish in highly-proficient CatalanSpanish bilinguals, half of them having Spanish, the other half having Catalan as their L1. They examined two types of Spanish irregular verbs, i.e. semi-regular verbs with a systematic diphthong alternation (e.g. sentir - siento 'feel'), and verbs with idiosyncratic changes (e.g. venir - viengo 'come'), and compared them against regular Spanish inflection (e.g. ganargano 'win'). In their overt priming study, both prime and target recognition were combined with a task for participants (letter search and lexical decision, respectively). RT measurements yielded the same priming effects for all morphological conditions irrespective of regularity. However, ERP patterns revealed differences between the speaker groups as well as between the types of irregular morphology. Regular verb pairs revealed a significant reduction of the N400 component in Spanish, irrespective of it being L1 or L2. Instead, irregular verb morphology elicited reduced N400 priming effects for both semi-regular and idiosyncratic item pairs in L2. However, when Spanish was the L1, the N400 was attenuated only for semiregular verb pairs. Consequently, De Diego Balaguer et al. (2005) argued that the similarity between languages might help for similar suffixations, but may interfere for dissimilar structures, such as Spanish verbs with idiosyncratic changes (e.g. venir - viengo 'come'). The fact that the RT data did not reveal significant differences between manipulated conditions, but ERP responses did, again shows that ERPs combined with the priming paradigm can add valuable information on the nature of activation of neural networks that would have remained undetected by sole RT measurements. 
More recently, Bosch et al. (2016) also combined RT and ERP measurements in two ERP cross-modal priming studies with advanced late Russian L2 learners of German. The crossmodal priming paradigm, in which the prime word is presented auditorily while the targets are presented in written form, has been argued to tap into modality-independent lexical entries encoding both grammatical and semantic information. The first of these experiments tested lemma-level priming effects comparing a test condition of related forms sharing the same lemma (e.g. neutrales - neutral 'neutral') to identical repetition priming (e.g. neutralneutral 'neutral') and unrelated controls (e.g. verbal - neutral 'verbal - neutral'). The second ERP priming experiment investigated morphosyntactic feature access in German inflected adjectives, such as geheim 'secret', which are marked for case, gender, and number, carrying inflectional affixes, such as -e, $-s$, and -m (e.g. geheim-e, geheim-es, geheim-em 'secret'). The $-m$ affix is regarded as the most specific one as it is restricted to datives ([+DAT]), followed by $-s$ and $-e$ which occur in both nominative and accusative case. In particular, priming effects between different inflected forms of the same adjectives (e.g. geheimes - geheime, geheimem - geheime 'secret') were compared to controls with identical primes and targets (e.g. geheime - geheime 'secret'). The ERP data revealed that prime-target pairs sharing the same lemmas yielded a reduced N400 in the L2, signalling facilitation in lexical retrieval similarly to the L1 control group (cf. Leminen \& Clahsen, 2014). However, morphologically related prime-target pairs yielded a reduced positivity for $-s$ and identity primes relative to primes with $-m$, reflecting the specificity of the $-m$ affix. For L1 speakers this positivity occurred early in the 200-300ms time window (cf. Leminen \& Clahsen, 2014), whereas for the L2 learner group, this effect started equally early, but yielded temporally and spatially extended brain responses. Hence, the processing of morphosyntax was interpreted to be more demanding and less automatic in advanced L2 learners of German. However, lexical-semantic processing seems to be alike in L1 and L2. Consequently, while previously collected L1 data indicated a temporal priority of grammatical information during processing, late bilinguals did 
not show any such precedence, but instead seemed to rely on grammatical and lexicalsemantic information in parallel.

Taken together, the two studies reviewed here clearly show the extra benefit of ERP measurements relative to pure behavioural measures. First, subtle neurophysiological processing differences between manipulated conditions can be tracked down more thoroughly (see de Diego Balaguer et al., 2005), and second, the exact time-course of morphosyntactic relative to lexical-semantic bilingual processing can be assessed more directly (see Bosch et al., 2016) - both such dimensions would have remained undetected by sole RT measurements. Overall, however, the few ERP priming studies on morphological and morphosyntactic processing are by far outnumbered by the existing ERP research making use of the violation paradigm (see e.g Rossi et al., 2006; Hahne et al., 2006; Weber \& Lavric, 2008). Those findings have, to some extent, supported the view that the L2 comprehension system employs real-time grammatical analysis less than the L1 system, but is instead more affected by nonstructural properties (Clahsen \& Felser, 2006a). However, ERP evidence for L1-like sensitivity to morphosyntax in advanced L2 speakers is growing. L2 learners have been claimed to process morphosyntactic features in a native-like way, but L1-like processing in an L2 may be faster for those unique structures which do not conflict with L1 structures (see e.g. Foucart \& Frenck-Mestre, 2012). Overall, these scarce morphological priming studies suggest a sensitivity of both early and late proficient L2 learners towards subtle morphological features. However, the differences between L1 and L2 in both studies indicate that the cortical processing of L2 morphology may be more laborious than that in L1, despite high proficiency in L2. 


\section{Research on semantic ERP priming}

The semantic priming paradigm, which probes activation at the conceptual level of the mental lexicon, has been used in several ERP studies to reveal the neural mechanisms of word-level lexical-semantic processes in the bilingual brain. Kotz (2001) and Kotz and Elston-Guettler (2004) used the overt priming techniques in L2 (relative to L1) speakers to investigate whether fluent bilingual speakers access conceptual representations equally fast and efficiently in their L1 and L2 or whether early acquisition of L2 still results in concept mediation of the L2 via the L1. While Kotz (2001) tested proficient Spanish-English bilinguals with a maximal L2 age of acquisition (AoA) of 4 years, Kotz and Elston-Guettler (2004) examined late L2 learners of English with a minimum AoA of 11 years belonging either to a high or a low proficiency group. Both categorically related prime-target pairs (junior - boy) as well as associatively related primes and targets sharing formal, semantic, and collocational information ( $\mathrm{girl}$ - boy) were used as experimental stimuli in these two overt priming studies. Stimuli were presented word by word and participants performed a lexical decision on each presented item. Kotz (2001) reported native-like N400 performance patterns for both categorical and associative priming, suggesting that L2 word-word and word-concept links were equally strong in the L1 and L2 groups. In contrast, Kotz and Elston-Guettler (2004) obtained L1-L2 differences. Namely, while both high and low proficient L2 speakers showed an N400 effect for associative priming, categorical priming did not elicit an N400 effect in the L2. These findings were taken to indicate that both proficiency and AoA are important determinants in the development of direct conceptual representations in the L2.

Similarly, Kerkhofs et al. (2006) used the semantic priming paradigm to investigate the effects of semantic and lexical-orthographic context on RTs and ERPs for interlingual homographs (orthographically identical word forms with a different meaning in L1 and L2). The pattern of behavioural effects found for interlingual homographs completely sharing their 
orthographic representation across languages is contradictory - with inhibitory, facilitative, or even null effects found for interlingual homographs relative to control words (e.g. Dijkstra et al., 1998; Lemhöfer \& Dijkstra, 2004; von Studnitz \& Green, 2002). The addition of ERP measurements in this domain of language research, however, provides more detailed information on bilingual language activation patterns. Kerkhofs et al. (2006) tested highlyproficient Dutch-English late bilinguals who performed a lexical decision task in their L2 (English) on prime-target pairs. Homographs like stem ('voice' in Dutch) were either preceded by semantically related (root) or unrelated (fool) prime words. Homographs resulted in longer RTs and increased N400 amplitudes compared to control words. In addition, the semantic priming N400 effect interacted with the word frequency of the homographs in both L1 (Dutch) and L2 (English). Kerkhofs et al. (2006) interpreted these findings in terms of language non-selective access, thus extending the BIA+ model (Dijkstra \& Van Heuven, 2002) to bilingual word recognition. According to this model, two readings of an interlingual homograph (e.g. stem, meaning 'voice' in Dutch) are represented by two orthographic lexical representations, one for each reading of the homograph. The analysis of the homograph then involves competition between the two readings, which is assumed to be modulated by the linguistic context, the experimental task, and the relative frequency of the two readings. Highfrequency words generally have a higher resting level of activation than low-frequency words. Therefore, they have an advantage when activated. However, when a homograph has a higher word frequency in the non-target language than in the target language, this yields extra competition, producing an inhibition effect compared to a one-language control word (Dijkstra \& Van Heuven, 2002).

The view that non-target language activation reaches up to the semantic level has been supported by Hoshino and Thierry's (2012) ERP study on English-Spanish interlingual homographs (e.g. pie meaning 'foot' in Spanish). Spanish-English late unbalanced bilinguals were presented with homographs as targets preceded by primes which were either related to 
the English or Spanish meaning (e.g. apple - pie; toe - pie, respectively), or were totally unrelated (e.g. bed-pie). A reduction in the N400 amplitude occurred when targets were preceded by semantically related primes for both the English (target language) and the Spanish (non-target language) meaning of the homographs. However, the relatedness effect was found in the window of a late positive component (LPC) between 500ms and 650ms, only for stimulus pairs related in English. The LPC has been associated with more explicit processing and re-evaluation of the stimuli (see Martin et al., 2010; Müller et al., 2010). These findings were interpreted to indicate that although both meanings of an interlingual homograph are activated, the meaning of the non-target language is inhibited after $400 \mathrm{~ms}$, while the interpretation corresponding to the target language is explicitly processed up to a later stage.

The experimental studies reviewed above have made an effort to provide an exclusively monolingual context in order to circumvent the intentional activation of the non-targeted language of bilingual speakers. However, Thierry and Wu (2007) showed that the taskirrelevant language is also automatically activated by implicit orthographic and/or phonological feature overlap of the critical words. Using a cross-script language combination (Chinese-English) paradigm, their study presented late and proficient Chinese-English bilinguals with English word pairs. Critically, the Chinese translations of half of the primetarget pairs shared one character. While the presence of the hidden overlapping Chinese character failed to affect participants' behavioral performance, it significantly modulated brain potentials, such that pairs with the critical hidden Chinese character yielded smaller N400 effects than pairs without this hidden overlap (replication of Chinese monolingual data). These findings indicate that English words were automatically and unconsciously translated into Chinese, thus supporting the view that L1 activation is an unconscious correlate of second-language comprehension. 


\section{Bilingual language processing in dual-language contexts}

In addition to examining lexical processing mechanisms within either L2 or L1, the ERP semantic priming paradigm has also been employed to assess language-selective access when both languages compete with each other. Studies in which bilinguals are presented with words in L1 and L2, activating both languages at the intended level, attempt to identify crosslanguage interactions in word processing. During the last decade, in particular, these experimental settings have been combined with ERP measurements in order to examine the time-course of the underlying processes involved in word-level cross-language interaction.

De Bruijn et al. (2001) studied effects of language context on the interpretation of DutchEnglish interlingual homographs. In this visual semantic priming study, Dutch native speakers and L2 learners of English saw triplets of words with the first word determining the language context (Dutch vs. English) and the following two words serving as prime and as target (e.g. house (language context: English) - angel (prime) - heaven (target)). Participants performed a generalized lexical decision task responding 'yes' if all tree items were correct English and/or Dutch words, and 'no' if one or more words did not exist in either language. Despite the fact that semantically related items yielded a reduced N400 effect relative to unrelated ones, its amplitude was not modulated by the language context given by the first word of the triplet. Since Dutch language context did not inhibit the English meaning of the respective homograph, but instead, both meanings were activated, the authors argued in favour of a strong bottom-up role in bilinguals language processing supporting the BIA model of language non-selective access.

In the last two decades, many behavioural studies have investigated masked priming effects with non-cognate translation prime-target pairs (e.g. plage-beach). In the masked priming paradigm, primes are hidden by a previously presented mask (i.e. usually a series of hash marks) and only subconsciously perceived due to extremely short presentation times 
before target words are presented. Masked priming has been argued to tap into modalityspecific access representations defining the route by which information in the sensory input is linked to a given lexical entry (Marslen-Wilson et al., 1994: 4). Thus, this priming technique has been argued to be more sensitive to sublexical form-level effects than to semantic effects (Forster, 1998). Masked translation priming studies established an asymmetric priming pattern with faster responses on L2 targets when preceded by their L1 translation compared to L2 targets preceded by an unrelated L1 word.

Combined translation priming and ERP studies have further investigated the degree of the lexical representation of one language being shared with the other language. Their main purpose is to track down the time-course of the activation of non-cognate translation equivalents (e.g. Midgley et al., 2009; Hoshino et al., 2010; Schoonbaert et al., 2010). So far, two ERP components have reflected masked translation priming ERP effects: the N250 and the N400. Previous L1 ERP research (e.g. Holcomb and Grainger, 2006; Morris et al., 2007) reported that repetition priming is seen in the reduction of both the N400 component and a negative-going waveform peaking around $250 \mathrm{~ms}$ post stimulus onset. With the exception of very few studies, the $\mathrm{N} 250$ component has been argued to reflect the mapping of sublexical form representations (letters and letter clusters) onto whole word orthographic representations, thus being predominantly sensitive to form-overlap effects. Hence, the N250 component is larger for target words which are not full repetitions of or which had no overlap with their prime words (Holcomb \& Grainger, 2006).

In their masked repetition and translation priming study, Midgley et al. (2009) tested the predictions of the BIA model with respect to effects of non-cognate translation primes in unbalanced French-English bilinguals. They examined the nature of form-meaning interactions of individual words and assessed the exact time-course of form and meaning activation during (non-balanced) bilingual word recognition. Both within-language repetition and L1-L2 translation priming effects were assessed. The prime-target pairs were French- 
English translation equivalents with minimal form overlap (e.g. plage - beach). Midgley et al. (2009) found that the N250 component was modulated with respect to within-language repetition priming in both $\mathrm{L} 1$ and $\mathrm{L} 2$, as well as to non-cognate translation priming when primes were in the L1 and targets in the L2. No such N250 modulation was obtained when primes were in the L2 and targets in the L1. The N400, however, was sensitive to non-cognate translation priming in both language directions. These results were interpreted to be in line with the BIA model (Dijkstra \& Van Heuven, 2002), such that L1 primes rapidly activate the corresponding semantic representation which feeds back information to appropriate formlevel representations in L1 and L2, thus modifying the processing of L2 targets that are translations of the L1 prime (Midgley et al., 2009).

Similarly, investigating code-switching effects using an English-French primed picturenaming experiment, Chauncey et al. (2009) obtained different markers of the switch cost between English and French depending on the language direction. Late unbalanced bilinguals named picture targets that were preceded by masked word primes, which corresponded either to the name of the picture target or to an unrelated picture name. The authors found that switching from L2 (French) to L1 (English) yielded differences in the N400 component, but not in the N250 component. This was explained by the overall longer time required for L2 prime words to activate semantic representations compared to the time required for L1 primes (see also e.g. Midgley et al., 2009). In contrast, L1-L2 switch produced differences already in the N250, similarly to the repetition priming effect found in L1 studies. Furthermore, in their masked priming ERP study, Hoshino et al. (2010) investigated the time-course of cross-script translation priming and repetition priming in Japanese-English late bilinguals. Targets were preceded either by repetition primes, translation equivalents, or unrelated primes and participants were tested in both L1 (Japanese) and L2 (English). The results revealed that the N250 and the N400 were significantly modulated for repetition priming in both target languages. However, these ERP components were only influenced significantly by L1-L2 
translation priming, and not by L2-L1 prime-target combinations. Hoshino et al. (2010) argued for the influence of semantic overlap across primes and targets on the N250 via topdown feedback mechanisms.

Testing highly proficient simultaneous Basque-Spanish bilinguals, Dunabeitia et al. (2010) investigated the underlying electrophysiological correlates of the masked translation priming effects. They aimed to track down the time-course of automatic translation processes in bilinguals, and to investigate whether there is a symmetrical masked translation priming effect for non-cognate words. They presented their participants a set of Basque and Spanish primetarget pairs in an identical (e.g. cuento - cuento 'tale'), non-cognate translation (e.g. ipuincuento), and an unrelated control condition (e.g. huelga - cuento 'strike - tale'). The authors obtained a masked repetition priming effect seen in reduced N400 amplitudes in the noncognate translation conditions for both language directions (L1 - L2; L2 - L1),. However, there were no masked translation priming effects visible in the N250 component. The symmetrical N400 effects in both translation directions were interpreted to indicate a decrease of the effort needed to form links between lexical and semantic representations. This further suggests that for highly-proficient bilinguals, conceptual access is direct for words in both languages. The absence of the early automatic masked translation priming effects at the N250 time window contradicts the findings in Midgley et al. (2009) and Hoshino et al. (2010). It can be explained by the fact that all participants were balanced bilinguals who exhibit an "increased level of mutual interference and inhibition exerted by [their] L1 and [their] L2" (Dunabeitia et al., 2010, p. 150). Furthermore, the authors argued that the lack of N250 masked translation priming effects supports the traditional conception of the N250 being rather blind to semantic relationships between primes and targets.

Using a slightly different focus of detecting the mechanisms underlying language identification during reading, Casaponsa et al. (2015) explored the time-course of automatic language switch effects in bilingual word recognition. In particular, they studied how sub- 
lexical orthographic regularities of words are used as predictive cues by bilinguals to detect the language code. They conducted a masked priming study combined with a semantic categorization task with early Spanish-Basque bilinguals (with Spanish as dominant language) and Spanish monolingual controls as participants. Spanish target words (e.g. cuento 'story') were preceded by unrelated Spanish (e.g. bolsa 'bag') or unrelated Basque words, containing bigrams either plausible (e.g. mutil 'boy') or implausible (e.g. neska 'girl' containing 'sk' as implausible bigram in Spanish) in Spanish. Bilingual participants showed a masked language switch cost effect only for Basque primes with implausible bigrams, reflected in the increased N250 and N400 components, compared to unrelated Spanish primes. No effects were obtained for Basque primes with plausible bigrams in Spanish. Monolinguals, however, showed strong effects for both plausible and implausible masked strings. These data were taken as further evidence that statistical orthographic regularities of words determine bilingual language detection. This, in turn, corroborates the extension of the BIA+ model arguing for the critical role of the sub-lexical route in determining language membership information.

Taken together, the masked translation priming ERP studies reviewed above show that even an unconscious language switch produces a cognitive cost represented by modulations in the N250 and N400 ERP components. The observed pattern of negativities related to language switch cost effects has been repeatedly found in previous language switching ERP studies which have employed other experimental paradigms than priming (see e.g. Christoffels et al., 2007; Jackson et al., 2001; Proverbio et al., 2004).

\section{Conclusions}

In the last decades, ERPs have become an increasingly powerful tool for investigating language-related brain processes in second language learners and bilinguals. In particular, the 
studies reviewed above demonstrate that the combination of the priming and ERP techniques can provide a valuable method for diagnosing areas of difficulty for L2 learners. In addition, they allow identifying linguistic domains in which native-like language comprehension processes are not normally attained. A considerable amount of ERP priming research has been conducted in the field of semantic as well as translation priming. Overall, overt semantic priming studies suggest language non-selective lexical-semantic access and processing, revealed in modulations of the N400 component. Masked translation priming ERP studies have shown that an unconscious language switch produces a cognitive cost reflected mainly in the modulations of the $\mathrm{N} 250$ and $\mathrm{N} 400$ components. However, translation priming may also involve additional cognitive processes, such as executive functions, which might explain the presence of the N250 effect in addition to the purely lexical-semantic N400 component.

Our review also shows that to date, L2 ERP priming studies are only beginning to emerge particularly in the morphological and the syntactic priming domains. The few morphological ERP priming studies reviewed above suggest a somewhat less automatic processing of morphological information in both early and highly proficient late bilinguals. It is evident, however, that much more ERP evidence is needed on L2 morphological and syntactic priming in order to obtain a comprehensive view of the underlying mechanisms as well as the timecourse of bilingual language comprehension. In this respect, careful control of factors, such as age of acquisition and proficiency level, can help us to elucidate further the nature of the differences between native speakers, bilinguals, and multilinguals. 


\section{References}

Birdsong, D. (1992). Ultimate Attainment in Second Language Acquisition. Language, 68, 706-755.

Bosch, S. \& H. Clahsen (2016). Accessing morphosyntax in L1 and L2 word recognition: A priming study of inflected German adjectives. The Mental Lexicon, 11, 26-54.

Bosch, S., Krause, H., \& Leminen, A. (2016). The time-course of morphosyntactic and semantic priming in late bilinguals: A study of German adjectives. Bilingualsim: Language and Cognition, available on CJO 2016 doi:10.1017/ S1366728916000055.

Casaponsa, A., Carreiras, M., \& Dunabeitia, J.A. (2015). How do bilinguals identify the language of the words they read? Brain Research, 1624, 153-166.

Chauncey, K., Holcomb, P.J., \& Grainger, J. (2009). Primed picture naming within and across languages: an ERP investigation. Cognitive, Affective, \& Behavioral Neuroscience, 9, 286303.

Christoffels, I.K., Firk, C., \& Schiller, N.O. (2007). Bilingual language control: an eventrelated brain potential study. Brain Research, 1147, 192-208.

Clahsen,H. \& Felser,C. (2006a).How native-like is non-native language processing? Trends in Cognitive Sciences, 10, 564-570.

De Bruijn, E., Dijkstra, T., Chwilla, D., \& Schriefers, H. (2001). Language context effects on interlingual homograph recognition: evidence from event-related potentials and response times in semantic priming. Bilingualsim: Language and Cognition, 4, 155-168.

de Diego Balaguer, R., Sebastián-Gallés, N., Diaz, B., \& Rodriguez-Fornells, A. (2005). Morphological processing in early bilinguals: An ERP study of regular and irregular verb processing. Cognitive Brain Research, 25, 312-327. 
Dijkstra, A., Van Jaarsveld, H., \& Ten Brinke, S. (1998). Interlingual homograph recognition: Effects of task demands and language intermixing. Bilingualism: Language and Cognition, $1,51-66$.

Dijkstra, A.F.J. \& Van Heuven, W.J.B. (2002). The architecture of the bilingual word recognition system: From identification to decision. Bilingualism: Language and Cognition, 5, 175-197.

Dominguez, A., de Vega, M., \& Barber, H. (2004). Event-related brain potentials elicited by morphological, homographic, orthographic, and semantic priming. Journal of Cognitive Neuroscience, 16, 598-608.

Dunabeitia, J., Dimitropoulou, M., Uribe-Etxebarria, O., Laka, I., \& Carreiras, M. (2010). Electrophysiological correlates of the masked translation priming effect with highly proficient simultaneous bilinguals. Brain Research, 1359, 142-154.

Dunabeitia, J.A., Dimitropoulou, M., Gillon Dowens, M., Molinaro, N., \& Martin, C. (2016). The electrophysiology of the bilingual brain. In R.R. Heredia, J. Altarriba, \& A.B. Cieslicka (Eds.), Methods in bilingual reading comprehension research (pp. 265-312), New York: Springer.

Flege, J., MacKay, I., \& Meador, D. (1999). Native Italian speakers' production and perception of English vowels. Journal of the Acoustical Society of America, 106, 29732987.

Forster, K.I. (1998). The pros and cons of masked priming. Journal of Psycholinguistic Research, 27, 203-233.

Foucart, A. \& Frenck-Mestre, C. (2012). Can late L2 learners acquire new grammatical features? Evidence from ERPs and eye-tracking. Journal of Memory and Language, 66, $226-248$. 
Hagoort, P., Baggio, G., \& Willems, R. M. (2009). Semantic unification. In M. S. Gazzaniga (Ed.), The Cognitive Neurosciences. (Vol. Fourth, pp. 819-837). Cambridge, Massachusets: MIT Press.

Hahne, A., Müller, J., \& Clahsen, H. (2006). Morphological processing in a second language: behavioral and event-related brain potential evidence for storage and decomposition. Journal of Cognitive Neuroscience, 18, 121-134.

Holcomb, P.J. \& Grainger, J. (2006). On the time course of visual word recognition: an eventrelated potential investigation using masked repetition priming. Journal of Cognitive Neuroscience, 18, 1631-1643.

Hoshino, N., \& Thierry, G. (2012). Do Spanish-English Bilinguals have Their Fingers in Two Pies - or is It Their Toes? An Electrophysiological Investigation of Semantic Access in Bilinguals. Frontiers in Psychology, 3, 9. http://doi.org/10.3389/fpsyg.2012.00009.

Hoshino, N., Midgley, K.J., Holcomb, P.J., \& Grainger, J. (2010). An ERP investigation of masked cross-script translation priming. Brain Research, 1344, 159-172.

Jackson, G. M., Swainson, R., Cunnington, R., \& Jackson, S. R. (2001). ERP correlates of executive control during repeated language switching. Bilingualism, 4, 169-178.

Johnson, J.S. \& Newport, E. (1989). Critical period effects in second language learning: the influence of maturational state on the acquisition of English as a second language. Cognitive Psychology, 60-99.

Kerkhofs, R., Dijkstra, T., Chwilla, D., \& de Bruijn, E. (2006). Testing a model for bilingual semantic priming with interlingual homographs: RT and N400 effects. Brain Research, $1068,170-183$.

Kielar, A., \& Joanisse, M. F. (2010). Graded effects of regularity in language revealed by N400 indices of morphological priming. Journal of Cognitive Neuroscience, 22, 13731398. 
Kielar, A., \& Joanisse, M. F. (2011). The role of semantic and phonological factors in word recognition: An ERP cross-modal priming study of derivational morphology. Neuropsychologia, 49, 161-177.

Kotz, S. \& Elston-Guettler, K. (2004). The role of proficiency on processing categorial and asociative information in the $\mathrm{L} 2$ as revealed by reaction times and event-related brain potentials. Journal of Neurolinguistics, 17, 215-235.

Kotz, S.A. (2001). Neurolinguistic evidence for bilingual language representation: a comparison of reaction times and event related brain potentials. Bilingualism: Language and Cognition, 4, 143-154.

Krause, H., Bosch, S., \& Clahsen, H. (2015). Morphosyntax in the bilingual mental lexicon. An experimental study of strong stems in German. Studies in Second Language Acquisition, doi:10.1017/S0272263114000564.

Kutas, M., \& Federmeier, K. D. (2000). Electrophysiology reveals semantic memory use in language comprehension. Trends in Cognitive Sciences, 4, 463-470.

Kutas, M., \& Federmeier, K. D. (2011). Thirty years and counting: Finding meaning in the [400N] component of the event-related brain potential (ERP). Annual Review of Psychology, 62, 14.1-14.27.

Lavric, A., Clapp, A., \& Rastle, K. (2007). ERP evidence of morphological analysis from orthography: a masked priming study. Journal of Cognitive Neuroscience, 19, 866-877.

Lehtonen, M., Cunillera, T., Rodriguez-Fornells, A., Hulten, A., Tuomainen, J., \& Laine, M. (2007). Recognition of morphologically complex words in Finnish: Evidence from eventrelated potentials. Brain Research, 1148, 123-137.

Leinonen, A., Gronholm-Nyman, P., Jarvenpaa, M., Soderholm, C., Lappi, O., Laine, M., et al. (2009). Neurocognitive processing of auditorily and visually presented inflected words and pseudowords: Evidence from a morphologically rich language. Brain Research, 1275, $54-66$. 
Lemhöfer, K.M.L., \& Dijkstra, A.F.J. (2004). Recognizing cognates and interlingual homographs: Effects of code similarity in language specific and generalized lexical decision. Memory and Cognition, 32, 533-550.

Leminen, A., \& Clahsen, H. (2014). Brain potentials to inflected adjectives: beyond storage and decomposition. Brain Research, 1543, 223-234.

Marslen-Wilson, W., Tyler, L., Waksler, R., \& Older, L. (1994). Morphology and meaning in the English mental lexicon. Psychological Review, 101, 3-33.

Martín, M.C., Macizo, P., \& Bajo, T. (2010). Time course of inhibitory processes in bilingual language processing. British Journal of Psychology, 101(4), 679-93.

Midgley, K.J., Holcomb, P.J., \& Grainger, J. (2009). Masked repetition and translation priming in second language learners: a window on the time-course of form and meaning activation using ERPs. Psychophysiology, 46, 551-565.

Morris, J., Frank, T., Grainger, J., \& Holcomb, P.J. (2007). Semantic transparency and masked morphological priming: an ERP investigation. Psychophysiology, 44, 506-521.

Morris, J., Grainger, J., \& Holcomb, P. J. (2008). An electrophysiological investigation of early effects of masked morphological priming. Language and Cognitive Processes, 23, $1021-1056$.

Mueller, J. L. (2005). Electrophysiological correlates of second language processing. Second Language Research, 21, 152-174.

Müller, O., Duñabeitia, J.A., \& Carreiras, M. (2010). Orthographic and associative neighborhood density effects: What is shared, what is different? Psychophysiology, 47(3), 455-466.

Münte, T., Say, T., Clahsen, H., \& Kutas, M. (1999). Decomposition of morphologically complex words in English: evidence from event-related brain potentials. Cognitive Brain Research, 7, 241-253. 
Proverbio, A.M., Leoni, G., \& Zani, A. (2004). Language switching mechanisms in simultaneous interpreters: An ERP study. Neuropsychologia, 42, 1636-1656.

Rodriguez-Fornells, A., Muente, T., \& Clahsen, H. (2002). Morphological priming in Spanish verb forms: An ERP repetition priming study. Journal of Cognitive Neuroscience, 14, 443454.

Rossi, S., Gugler, M. F., Friederici, A. D., \& Hahne, A. (2006). The impact of proficiency on syntactic second-language processing of German and Italian: Evidence from Eventrelated potentials. Journal of Cognitive Neuroscience, 18, 2030-2048.

Rugg, M.D. (1995). ERP studies of memory. In M.D. Rugg \& M.G.H. Coles (Eds.), Electrophysiology of mind: Event-related brain potentials and cognition (pp.132-170), Oxford, UK: Oxford University Press.

Schoonbaert, S., Holcomb, P.J., Grainger, J., \& Hartsuiker, R.J. (2010). Testing asymmetries in noncognate translation priming: Evidence from RTs and ERPs. Psychophysiology 1-8.

Thierry, G., \& Wu, Y.J. (2007). Brain potentials reveal unconscious translation during foreign language comprehension. Proceedings of the National Academy of Science, 104, 1253012535.

Von Studnitz, R. E., \& Green, D. W. (2002). The cost of switching language in a semantic categorization task. Bilingualism, 5, 241-251.

Weber, K., \& Lavric, A. (2008). Syntactic anomaly elicits a lexico-semantic (N400) ERP effect in the second language but not the first. Psychophysiology, 45, 920-925.

Weber-Fox, C. M., \& Neville, H. J. (1996). Maturational constraints on functional specializations for language processing: ERP and behavioral evidence in bilingual speakers. Journal of Cognitive Neuroscience, 8, 231-256.

Weyerts, H., Münte, T. F., Smid, H. G. O. M., \& Heinze, H. J. (1996). Mental representations of morphologically complex words: An event-related potential study with adult humans. Neuroscience Letters, 206, 125-128. 